\title{
Physician Gender and Hormone Replacement Therapy Discussion
}

\author{
SALLY HUSTON, M.S., ${ }^{1}$ BETSY SLEATH, Ph.D. ${ }^{2}$ and RICHARD H. RUBIN, M.D. ${ }^{3}$
}

\begin{abstract}
Hormone replacement therapy (HRT) is a major issue confronting millions of women today, and general internal medicine and family practice physicians are an important source of information and counseling on this issue. Previous studies have suggested that HRT discussion and prescribing are more frequent with female than with male physicians, but others have suggested age and practice setting may be the reason for observed differences. We attempted to determine if physician gender influenced HRT discussion frequency between physicians and their patients using cross-sectional, secondary analysis of data collected at general internal medicine and family practice clinics at the University of New Mexico Health Sciences Center. Twenty-seven family practice and internal medicine resident physicians (15 female, 12 male) participated. There were 127 female patients age 45 and older. Audio-taped observations of patient-physician visits collected during 1995 for a study on patient-physician communication and patient satisfaction were used. There was less frequent discussion with female than male physicians $(\mathrm{OR}=0.42, p=0.0014)$. HRT was discussed during 51 visits. Patients initiated HRT discussion in $39.2 \%$ of visits in which it was discussed. Patients with diabetes were less likely to discuss HRT $(O R=0.25, p=0.0122)$. Increasing year of physician residency was associated with decreased discussion of HRT (OR $=0.51, p<0.0001)$. In this health sciences center, with physicians similar in age and training, male physicians discussed HRT significantly more often than did female physicians.
\end{abstract}

\section{INTRODUCTION}

$\mathbf{H}$ ORMONE REPLACEMENT THERAPy (HRT) is a major issue confronting millions of women today. By the year 2005, it is estimated that there will be more than 32 million women between the ages of 44 and $65 .^{1}$ Physicians have been found to be an important and primary source of infor- mation about menopause and HRT for women. ${ }^{2-7}$ Several medical organizations have published guidelines concerning HRT use, with the recommendation that all women should be counseled about the risks and benefits. ${ }^{8-10}$ The importance of this issue is underscored by the addition of a measure concerning management of menopause (MoM) counseling to the Health Plan Employer

\footnotetext{
${ }^{1}$ University of Michigan, College of Pharmacy, Ann Arbor, Michigan.

${ }^{2}$ University of North Carolina at Chapel Hill, School of Pharmacy, Chapel Hill, North Carolina.

${ }^{3}$ University of New Mexico, School of Medicine, Albuquerque, New Mexico.

Data were collected at the University of New Mexico, General Medicine and Family Practice Clinics during 1995.

This work was supported by funding from Wyeth-Ayerst Pharmaceuticals, Protocol 0713X1-990, secondary analysis of existing data, and Bayer Institute for Health Communication (grant number not applicable, primary data collection).
} 
Data and Information Set (HEDIS) for the year $2000 .{ }^{11}$ Internal medicine and family practice physicians are especially important in the area of HRT counseling. In a 1988 survey, 58\% of internists, compared with only $8 \%$ of gynecologists, reported the majority of their female patients were older than 50 years of age. ${ }^{12}$ Data from the 1993 and 1994 National Ambulatory Medical Care Surveys (NAMCS) also suggest that the majority of medical visits of women older than 40 years of age are to general internal medicine and family practice physicians, with $41 \%$ to general internists, $28 \%$ to family physicians, $18 \%$ to general practitioners, and only $12 \%$ to obstetrician/gynecologists. ${ }^{13}$

Some studies have suggested that menopausal patients are more likely to be prescribed HRT by female physicians than by male physicians. ${ }^{12,14}$ If HRT prescribing does vary with physician gender, it is important to understand why. Knowledge about the underlying process will enhance the ability of healthcare providers to take appropriate action and to provide effective care. Greendale et al. ${ }^{12}$ found that patients with female physicians were 11 times more likely to be prescribed HRT than patients with male physicians in a study that included general internists and gynecologists. Seto et al., ${ }^{14}$ in a study with primarily general internal medicine physicians, found that patients with female physicians received HRT $45 \%$ of the time versus $23 \%$ of patients with male physicians $(p<0.001)$. They also found, based on survey results, that primary care physicians were more likely to initiate discussion concerning HRT than other physicians or than patients themselves and that female physicians were more likely to initiate discussion than were male physicians. Lacroix et al. ${ }^{15}$ have suggested that the differences seen in the Seto et al. study ${ }^{14}$ may have been related to the region of the country and practice setting rather than to the gender of the physician. A survey by Ghali et al. ${ }^{16}$ found that although HRT prescribing was similar between male and female physicians, female physicians appeared to spend more time discussing menopausal issues with their patients. This was assessed by physician awareness of patient attitudes (attitudinal mismatch , $p=0.03$ ). Berman et al. ${ }^{17}$ found that decreased compliance with HRT (odds ratio [OR] $1.3,95 \%$ confidence interval [CI] 0.99-1.6) was associated with having a male physician. Variables in the Berman et al. study were determined through prescription and insurance claims data- bases. Although they mention the idea of "lack of rapport" as a possible contributor to decreased HRT adherence, they did not specifically attribute this to physician gender. ${ }^{17}$

Physician gender has been found to differ in regard to other gender-congruent preventive care rates as well. Using claims data with a group of 24,713 women, Lurie et al. ${ }^{18}$ found that patients of female internal medicine and family practice physicians were more likely to receive a Pap smear (OR 2.14, 95\% CI 1.83-2.51) or a mammogram (OR 1.50, 95\% CI 1.29-1.76). Franks and Clancy, ${ }^{19}$ using data from the 1987 National Medical Expenditure Survey, found lower rates of gender-congruent screening tests, such as Pap tests (risk ratio [RR] 0.61, 95\% CI 0.38-0.99) and mammograms (RR 0.63, 95\% CI 0.46-0.86), with male physicians, although there was not a significant difference for breast examinations and no difference in the use of blood pressure screening. They suggested that physician age or patient differences might account for the observed effects.

Therefore, this study examined initiation of discussion about the topic of HRT between physicians and patients, with physicians having comparable levels of training and age. An important difference between this and previous studies is that the current study was based on actual taped observations of patient-physician visits. We hypothesized that there would be more frequent discussion concerning HRT between female physicians and their patients than between male physicians and their patients. We also hypothesized that female physicians would initiate HRT discussion more frequently than male physicians and that patients would be more likely to initiate discussion with a female physician than with a male physician.

Several other factors previously have been found to have an influence on HRT use or on patient-physician communication. Increasing patient age has been associated with decreased HRT use, $^{20,21}$ whereas increasing educational levels have been associated with greater HRT use. ${ }^{20,22}$ Several recent studies suggest that women with diabetes use HRT less often than do women without diabetes. ${ }^{13,23,24}$ It has been recommended that HRT be discussed with women who have experienced signs or symptoms of estrogen deficiency, ${ }^{9}$ which can begin during perimenopause. ${ }^{25}$ Because the age for natural menopause and perimenopause varies, it is possible that not all women in the sample will have hypoestro- 
genism. ${ }^{26}$ Therefore, presence or absence of perimenopause or menopause was included in the study, as this could influence discussion. A diagnosis of hysterectomy previously has been associated with higher rates of HRT use. ${ }^{20}$ Non-Hispanic white women were found to be more likely to use HRT than Hispanic women. ${ }^{21}$ Therefore, these factors were also examined in this study.

\section{MATERIALS AND METHODS}

\section{Study design}

This was a cross-sectional, secondary analysis of transcripts and audiotaped observations of patient-physician visits collected during 1995.

\section{Study site}

The data for this study were collected at the University of New Mexico Health Sciences Center's general medicine and family practice clinics during 1995. Both of these clinics serve a large population of Hispanic, uninsured, and indigent patients. More than $95 \%$ of patients, including the uninsured and indigent, could receive prescriptions for a low nominal fee. Bilingual research assistants recruited patients and physicians. Both patients and physicians completed consent forms available in English and Spanish. These forms allowed the audiotaped visits, medical records, and questionnaires to be reviewed and used to study patient-physician communication.

\section{Dataset}

The data were originally collected for a study examining physician-patient communication and patient satisfaction and were not previously used to examine HRT discussion. The existing dataset included transcripts of audiotaped patient-physician interviews, medical records, and information from questionnaires.

\section{Physicians}

The physician sample was a convenience sample. Twenty-seven resident physicians were included in the original study, including 16 from the general medicine clinic and 11 from the family practice clinic. All resident physicians in the two clinics were randomly selected to participate, and of the physicians who were approached, $90 \%$ agreed to participate in the study. Those who did not agree to participate were not significantly different in terms of gender, ethnicity, age, year in residency program, or specialty from those who did agree to participate.

\section{Patients}

The patient sample was a convenience sample. All the eligible patients of each participating physician were recruited at all the physicians' scheduled clinic times. In almost all cases, a patient was assigned to a resident physician for the entire time the physician was in his or her residency program unless the patient wanted to change physicians. Original patient inclusion criteria were (1) 18 years of age or older, (2) gave full voluntary consent for study participation, and (3) able to communicate fluently in English or Spanish. Each patient was included only once. Seventy-nine percent of the approached patients agreed to participate in the study. There were 427 male and female patients in the original study. Patients who refused to participate did not differ significantly in terms of gender, ethnicity, age, or reason for clinic visit. The subset of the patients included in this study were (1) female, (2) $\geq$ age 45, and (3) non-Hispanic white or Hispanic. A lower age limit of 45 was selected to maximize the number of HRT discussions observed while minimizing visits with women for whom HRT would not be relevant. Patients who classified themselves as other than Hispanic or non-Hispanic white were excluded because of low sample representation. Patients with a record of a tamoxifen prescription or a diagnosis of breast cancer were excluded because breast cancer is often considered a contraindication to HRT. ${ }^{27}$ All patients from the original study meeting the criteria for this study were included. There were 130 female Hispanic or non-Hispanic patients aged $\geq 45$ in the study sample.

\section{Measurement}

Patient and physician demographic characteristics were determined from questionnaire data. Patient and physician gender were measured as dichotomous variables. Patient ethnicity was selfdetermined and measured as a dichotomous variable (Hispanic or non-Hispanic white). Patient age was measured in years as a continuous variable, as was years of schooling completed. Physician age was a continuous variable. Medical 
diagnoses were diabetes, menopause or perimenopause, and hysterectomy and were each measured as dichotomous variables. They were measured as Yes if the diagnosis was listed anywhere in the patient's medical chart up to and including the day of the patient-physician visit.

HRT discussion was determined through content analysis of the patient-physician visit transcripts. Several transcriptionists transcribed the audiotapes in English or in Spanish or both as spoken during the patient-physician visit. All the tapes were then reviewed by either the investigators of this study or one of two Spanish-speaking assistants in order to identify and correct errors and to ensure accuracy. Trained research assistants, one of whom was a fluent Spanish speaker, coded the transcripts using a coding tool developed by the principal investigator. HRT discussion included statements or questions by either the patient or the physician about HRT but excluded conversation related simply to identifying what medications the patient was taking. For example, it did not include simply naming an HRT drug in response to a question, such as "What medicines are you taking now?" Previous studies have not provided a clear definition of the term HRT discussion, and it is possible that some respondents could have interpreted this term differently. 3,14 HRT discussion was measured as a dichotomous variable, either Yes or No. When HRT was discussed, who initiated discussion was classified as a dichotomous variable, physician or patient.

Twenty-nine transcripts were randomly selected to assess intercoder reliability. Cohen's kappa was used for the nominal variables of whether or not HRT was discussed and, when HRT was discussed, who initiated HRT discussion. Cohen's kappa for HRT discussed was 0.861. Cohen's kappa for who initiated discussion was 0.882 . Kappa values $>0.75$ are considered excellent; values from 0.40 to 0.75 are considered $\operatorname{good}^{28}$

\section{Data analysis}

The unit of analysis was the patient-physician visit. There were 130 visits with female patients age $\geq 45$. Data were missing for three visits. This resulted in a final sample size of 127 visits, each with a different patient. First, descriptive statistics were calculated for the patient and physician demographic characteristics, using SPSS 9.0.0 for
Windows, standard version (SPSS, Inc., Chicago, IL). Then, bivariate relationships between the independent variables were explored. Chi-square tests, $t$ tests, and Pearson's correlation coefficients were calculated for the relationships between the independent variables and between the independent and dependent variables. The chi-square test was used to examine the relationship between physician gender and who introduced the subject of HRT.

Hierarchical modeling was used to predict the relationship between HRT discussion and the patient and physician variables. Patient demographic and medical history variables and physician gender were entered into a generalized estimating equation (GEE) logistic regression model, using SAS version 6.12 TS060 (SAS Institute, Inc., Cary, NC), in order to estimate the hierarchical model. Hierarchical modeling accounts for patient nesting within physician, by adjusting the standard errors of the regression coefficients. ${ }^{29,30}$

\section{Results}

Patients ranged in age from 45 through 83 . There were 78 Hispanic patients, $61.4 \%$ of the study sample. Patients with diabetes comprised $29.1 \%$ of the sample. The prevalence of non-insulin dependent diabetes (NIDD) is 2-3 times higher among Mexican Americans than it is in non-Hispanic whites. ${ }^{31}$ Approximately $82 \%$ of the patients had a diagnosis of menopause or hysterectomy, with $46.5 \%$ having a diagnosis of hysterectomy and $60.6 \%$ with a diagnosis of menopause/perimenopause recorded in the medical chart. Table 1 shows patient characteristics.

There were 27 physicians in the current study, $44.4 \%$ male and $55.6 \%$ female. The mean age of the physicians was 31.2 years, varying from 26 to 39 years. Fifty-nine percent of the physicians practiced in the general medicine clinic, and $41 \%$ were in the family practice clinic. There was no significant difference in the ages and genders of the physicians between or within clinics.

With each patient having a single visit, the number of audiotaped visits with each physician varied from 1 to 11 , with the mean number of visits per physician being 4.85 . There was no significant difference in the number of visits between male and female physicians, although the mean number of visits with female physicians was slightly higher (5.07) than with male physicians 
Table 1. Patient and Physician Characteristics and NuMbER OF VisITS DURING WHICH HRT WAS Discussed $(n=127)$

\begin{tabular}{|c|c|c|}
\hline $\begin{array}{l}\text { Patient } \\
\text { characteristics }\end{array}$ & $\begin{array}{c}\text { No. (\%) } \\
\text { of patients } \\
\text { with } \\
\text { characteristic }\end{array}$ & $\begin{array}{c}\text { No. (\%) of } \\
\text { visits with } \\
\text { characteristic with } \\
\text { HRT discussed }\end{array}$ \\
\hline \multicolumn{3}{|l|}{ Ethnicity } \\
\hline Hispanic & 78 (61.4) & 28 (35.9) \\
\hline $\begin{array}{l}\text { Non-Hispanic } \\
\text { white }\end{array}$ & 49 (38.6) & $23(46.9)$ \\
\hline \multicolumn{3}{|l|}{ Age, years } \\
\hline $45-54$ & $58(45.7)$ & $26(44.8)$ \\
\hline $55-64$ & $52(40.9)$ & $21(40.4)$ \\
\hline$\geq 65$ & 17 (13.4) & $4(23.5)$ \\
\hline Total & $127(100)$ & $51(40.2)$ \\
\hline \multicolumn{3}{|l|}{ Education, years } \\
\hline $0-11$ & $60(47.2)$ & $24(40.0)$ \\
\hline 12 & $34(26.8)$ & $14(41.2)$ \\
\hline$\geq 13$ & $33(26.0)$ & $13(39.4)$ \\
\hline \multicolumn{3}{|l|}{ Diabetes* } \\
\hline Yes & $37(29.1)$ & $10(27.0)$ \\
\hline No & $90(70.9)$ & $41(45.6)$ \\
\hline \multicolumn{3}{|c|}{$\begin{array}{l}\text { Menopause/ } \\
\text { Perimenopause }\end{array}$} \\
\hline Yes & 77 (60.6) & $38(49.4)$ \\
\hline No & $50(39.4)$ & $13(26.0)$ \\
\hline \multicolumn{3}{|l|}{ Hysterectomy*** } \\
\hline Yes & $59(46.5)$ & $30(50.8)$ \\
\hline No & 68 (53.5) & $21(30.9)$ \\
\hline $\begin{array}{l}\text { Physician } \\
\text { characteristics }\end{array}$ & $\begin{array}{l}\text { No. (\%) of } \\
\text { visits with } \\
\text { physician } \\
\text { characteristic }\end{array}$ & $\begin{array}{c}\text { No. (\%) of } \\
\text { visits with } \\
\text { characteristic with } \\
\text { HRT discussed }\end{array}$ \\
\hline \multicolumn{3}{|l|}{ Gender } \\
\hline Male & $54(42.5)$ & $25(46.2)$ \\
\hline Female & 73 (57.5) & $26(35.6)$ \\
\hline \multicolumn{3}{|l|}{ Residency year } \\
\hline First & 49 (38.6) & $25(51.0)$ \\
\hline Second & $41(32.3)$ & $16(39.0)$ \\
\hline Third & $37(29.1)$ & $10(27.0)$ \\
\hline
\end{tabular}

Significance level for two-sided Pearson chi-square test: ${ }^{*} p=0.053 ;{ }^{* *} p=0.009 ;{ }^{* * *} p=0.022$.

(4.58). There was no significant difference in the number of visits between the two clinics, with a mean of 4.5 visits per physician in the general internal medicine clinic and a mean of 5.36 visits in the family practice clinic.

HRT was discussed with 27 physicians, 15 female and 12 male, during 51 visits. It is important to note that guidelines suggest that HRT be discussed with all women at some point but not necessarily during each visit. Additionally, not all women in the sample were menopausal. Therefore, it was not expected that HRT would be dis- cussed during all visits. Table 1 also presents the patient and physician characteristics during visits in which HRT was discussed. HRT was discussed during $35.6 \%$ of visits with female physicians and during $46.2 \%$ of visits with male physicians. Overall, the patient introduced the subject of HRT 20 times, 39.2\% of the time. Chisquare analysis of the association between physician gender and who initiated HRT discussion found no significant difference (Table 2).

Interestingly, HRT was discussed significantly less during visits with patients with diabetes $(27.0 \%)$ than with patients without diabetes $(45.6 \%)$ (Pearson chi-square $=3.75, p=0.053)$. As expected, HRT was discussed more often with patients who had a recorded diagnosis of menopause $(49.4 \%)$ than it was discussed with patients without a recorded diagnosis of menopause $(26.0 \%$ ) (Pearson chi-square $=6.9, p=$ 0.009 ). HRT was discussed during $50.8 \%$ of visits with a recorded diagnosis of hysterectomy and during only $30.9 \%$ of visits without such a diagnosis (Pearson chi-square $=5.24, p=0.022$ ). There were no significant differences found in the relationships between HRT discussion and the variables of ethnicity, age group, educational level, or year of physician residency.

Table 3 presents the results of the GEE analysis predicting discussion of HRT during the patient-physician visit. After accounting for clustering by physician, results indicate that female physician gender was significantly associated with a lower likelihood of HRT discussion during the patient-physician visit $(\mathrm{OR}=0.42, p=$ 0.0014). Increasing patient age was significantly associated with decreased HRT discussion (OR = 0.94, $p=0.0185)$, although the effect was not large. Patients with diabetes were significantly less likely to have discussion concerning HRT during their visit $(\mathrm{OR}=0.26, p=0.0155)$. As expected, the medical diagnoses of menopause/ perimenopause $(\mathrm{OR}=4.67, p=0.0003)$ or hysterectomy $(\mathrm{OR}=1.98, p=0.0985)$ were associ-

Table 2. Gender of Physician When HRT Discussion WAS INITIATED

\begin{tabular}{lccc}
\hline Who initiated & $\begin{array}{c}\text { Male } \\
\text { physician } \\
\text { No. }(\%)\end{array}$ & $\begin{array}{c}\text { Female } \\
\text { physician } \\
\text { No. (\%) }\end{array}$ & Total No. \\
\hline Patient & $9(36.0)$ & $11(42.3)$ & 20 \\
Physician & $16(64.0)$ & $15(57.7)$ & 31 \\
$\quad$ Total & 25 & 26 & 51 \\
\hline
\end{tabular}


Table 3. Generalized Estimating Equation Predicting Discussion of HRT During the Patient-Physician Visit $(n=127$ Patients SeEing 27 Physicians $)$

\begin{tabular}{lccc}
\hline Independent variables & Estimate $(S E)$ & $95 \%$ confidence interval & Odds ratio \\
\hline Physician gender $(2=$ female, $1=$ male) & $-.87(.27)$ & $(-.34,-1.41)$ & $.42^{*}$ \\
$\begin{array}{l}\text { Patient ethnicity } \\
\quad(==\text { non-Hispanic white, } 1=\text { Hispanic) }\end{array}$ & $-.85(.55)$ & $(.23,-1.94)$ & .43 \\
Patient age (years) & $-.07(.03)$ & $(-.01,-.12)$ & $.94^{* *}$ \\
Patient schooling (years) & $-.09(.06)$ & $(.03,-.21)$ & .92 \\
$\begin{array}{l}\text { Diabetes } \\
\quad(0=\text { no, } 1=\text { yes) }\end{array}$ & $-1.34(.55)$ & $(-.25,-2.43)$ & $.26^{* * *}$ \\
$\begin{array}{l}\text { Menopause/perimenopause } \\
\quad(0=\text { no, } 1=\text { yes })\end{array}$ & $1.54(.43)$ & $(2.38, .70)$ & $4.67^{* * * *}$ \\
$\begin{array}{l}\text { Hysterectomy } \\
\quad(0=\text { no, } 1=\text { yes })\end{array}$ & $.68(.41)$ & $(1.49,-.13)$ & 1.98 \\
Residency year & $-.68(.14)$ & $(-.39,-.96)$ & $.51^{* * * * *}$ \\
\hline
\end{tabular}

${ }^{*} p=0.0014 ;{ }^{* *} p=0.0185 ;{ }^{* * *} p=0.0155 ;{ }^{* * * *} p=0.0003 ;{ }^{* * * * *} p=0.0001$.

ated with greater likelihood of HRT discussion. Physicians in their third year of residency were significantly less likely to discuss HRT with their patients than were second year or first year residents $(\mathrm{OR}=0.51, p<0.0001)$. Neither patient ethnicity nor education was significantly associated with HRT discussion likelihood. The number of previous visits with a physician was also tested and not found to be significant. Therefore, the final model did not include this factor.

\section{DISCUSSION}

Although we hypothesized that there would be more frequent HRT discussion with female physicians than with male physicians, we found that HRT was discussed significantly more often with male physicians (GEE analysis, $p=0.0014$ ). Based on empirical data from previous studies, this was unexpected. Seto et al. ${ }^{14}$ found that patients recalled HRT discussion with female physicians more frequently than with male physicians. Ghali et al. ${ }^{16}$ reported that female physicians discussed menopause more frequently than male physicians. In addition, results from one survey showed that $81 \%$ of women rated having a female physician available with whom to discuss menopause as being very important. ${ }^{5}$ It may be that there was more discussion about psychosocial or other gender-related issues during these visits, resulting in a lower percentage of visits with discussion about HRT with female physicians. Roter and Hall ${ }^{32,33}$ found greater discussion of psychosocial and socioemotional issues during visits with female physicians when com- pared with male physicians. Haar et al. ${ }^{34}$ found that psychotherapy patients were likely to prefer female gynecologists. They also found that women (including psychotherapy and nonpsychotherapy patients) preferring a female gynecologist tended to cite reasons that were related to greater understanding of women's problems or because of perceptions of "greater physical and emotional comfort." 34 Fennema et al. ${ }^{35}$ also noted that of $51 \%$ of patients expressing a preference for physician gender in regard to discussing depression and family problems, $41 \%$ preferred a woman. Discussion of psychosocial and socioemotional issues is important, and further study is needed to discover if this is indeed the reason that there was less discussion of HRT.

Physicians' age, regional variation, or differences in practice setting have been suggested as explaining differences in HRT recommendations and use, rather than gender. ${ }^{6,15,19}$ The Seto et al. study ${ }^{14}$ included physicians with a mean age of 32 (SD \pm 7 ) years. The mean physician age in the current study was 31.2 years, but the standard deviation was smaller ( $\mathrm{SD} \pm 3.9$ years). Therefore, the physicians included in this study were more comparable on age and level of training, reducing practice variations due to these factors. Seto et al. ${ }^{14}$ conducted their study in the northeast, whereas the current study was conducted in the southwest. Data from the 1993-1994 NAMCS suggest that the rate of HRT use is much higher in the west $(13.4 \%)$ than in the northeast $(3.9 \%){ }^{13}$

In the Albuquerque practice setting of this study, the American College of Physicians (ACP) guidelines for counseling postmenopausal women were widely available and promoted by the attending 
physicians to the resident general internal medicine physicians during the period in which data were collected. ${ }^{8}$ However, it is not clear that these guidelines were equally promoted to the family practice residents. Attending physicians in family medicine did emphasize keeping indicated preventive interventions up to date, including women's health issues, such as HRT. In addition, for both groups, there was a flow sheet in each patient's chart that outlined preventive interventions based on gender and age, including HRT. These flow sheets were in use during 1992 through 1995.

It is puzzling that counseling about HRT decreased with increasing residency year. Lack of time did not appear to be an issue, as first year residents were generally scheduled for longer rotations and were considered to have greater time pressures. It is possible that education about menopause and HRT differed before beginning their residency training. It is also possible that although the guidelines and flow sheets were widely disseminated throughout the training period of these residents, implementation of these practices was somewhat slower. In any case, the trend of decreasing discussion of HRT with increasing residency seniority is one of some concern and should be followed up in future research. Although other studies have suggested that passive dissemination is not particularly effective for increasing the use of guidelines, it is thought that social influences, such as opinion leaders, may be, ${ }^{36}$ and opinion leaders may be particularly effective in teaching settings. During training, each resident's case was discussed with an attending physician, and there were educational conferences that included the topic of HRT. However, data concerning HRT discussion by opinion leaders were not collected. Previous research suggests that using two or more methods of influencing physician behavior, as was done in this setting, is more successful in guiding change than is a single intervention. ${ }^{36,37}$

In the current study there was no significant difference between physician gender and HRT discussion initiation, although the small sample size precludes drawing a strong conclusion. This differs from the Seto et al. study, ${ }^{14}$ in which female physicians were reported to initiate HRT discussion more frequently than male physicians $(p=0.1)$. In addition, patients were equally likely to introduce the subject of HRT discussion with either a female or a male physician in this study.
It is very encouraging to know that male physicians are highly likely to discuss HRT with their female patients over the age of 45 and that female patients appear willing to initiate discussion about this important issue with both male and female physicians.

It is also very interesting that patients initiated discussion $39.2 \%$ of the time when HRT was discussed. This also differs from the Seto et al. study, ${ }^{14}$ which found that patients recalled initiating discussion during only 5 of 52 healthcare visits in which HRT was discussed. An advantage of the current study is that it was based on actual tape-recorded visits, and, therefore, did not rely on patient memory. Clearly, HRT is an important issue that women want to discuss with their physicians.

A diagnosis of diabetes was associated with significantly lower odds of discussing HRT. Because several recent studies have suggested that there is less use of HRT by women with diabetes when compared with those without diabetes, ${ }^{23,24}$ we expected that there might be less frequent discussions about HRT with women with diabetes. However, women with diabetes are also likely to have a higher number of visits to their physician, ${ }^{13}$ so it is possible that physicians have the same number of HRT discussions with both types of patients in any given year, but the percent of overall visits with HRT discussion may be lower for women with diabetes. Therefore, it is difficult to draw any firm conclusion from the results of this study, although it does suggest the possibility that HRT may not be discussed frequently enough with women with diabetes.

It is interesting that this study did not find a significant association between patient educational level and discussion of HRT. Previous studies have found an association between increased use of HRT and increasing levels of education. ${ }^{16,20,38}$ They did not, however, examine the issue of HRT discussion. Future research should examine the relationship among HRT discussion, educational level, and HRT use. It may be that even when the issue is discussed, educational level will play a role in the initiation and continuation of HRT.

A major limitation of this study is the small sample size, which limited its power. However, the fact that we conducted the study in only one health sciences center increased the comparability of the physicians. Another limitation of this study is that the physicians were all resident 
physicians. This is offset by the advantage of similarity of age, training level, and practice setting of these physicians, allowing a better gender comparison. Another limitation of the study is the cross-sectional design, as we were able to examine only one visit with each patient. Therefore, we were unable to capture any discussion concerning HRT that may have occurred in previous or subsequent visits. This should not affect the relationships between HRT discussion and physician gender, however, because the possibility of previous or subsequent discussion should be similar for both genders.

\section{CONCLUSIONS}

Although drawn from a convenience sample, this study provides important information about patient-physician communication about HRT and is one of the first examining this issue in which audiotapes of actual conversations were examined. In this health sciences center, with physicians similar in age and training, male physicians discussed HRT with their appropriate patients significantly more often than did female physicians. It is possible that more psychosocial and socioemotional discussion occurred between female physicians and their patients, and this resulted in less discussion concerning HRT. This should be investigated in future studies.

There was no significant difference by physician gender in who initiated discussions about HRT, but the small size of this sample limited the ability to test for this parameter. In this health setting, women did not appear more reluctant to discuss the topic with male physicians than they were with female physicians.

Although not a focus, this study also provides interesting information about HRT discussion with women who have diabetes. A trend toward decreased HRT discussion with increasing resident seniority is troubling and should be investigated. Future investigations may want to consider the role of opinion leaders, guideline dissemination, preventive care flow sheets, and reinforcement by attending physicians.

HRT is an important topic that all physicians should discuss with their perimenopausal and postmenopausal patients. Physicians should also discuss other important options for treating symptoms, preventing osteoporosis, and reducing heart disease. ${ }^{10}$ It has been shown previously that the recommendation of the physician is an important influence on the decision to use HRT. ${ }^{3}$ Findings of this study suggest that male physicians in a clinic setting similar to the one in Albuquerque are at least equally and possibly more likely than female physicians to discuss HRT with their appropriate patients. Future research should examine this topic in attending physicians.

\section{ACKNOWLEDGMENTS}

We thank Rhonda Aragon, Carlos Rojas, Summer Williams, and Kathy Welch for their assistance with this project.

\section{REFERENCES}

1. U.S. Census Bureau. Population Projections Program, Vol. 2000. Population Division, U.S.Census Bureau, 2000. http://www.census.gov accessed July 30, 2000.

2. Clinkingbeard C, Minton BA, Davis J, McDermott K. Women's knowledge about menopause, hormone replacement therapy (HRT), and interactions with healthcare providers: An exploratory study. J Women's Health Gender-Based Med 1999;8:1097.

3. Ferguson KJ, Hoegh C, Johnson S. Estrogen replacement therapy: A survey of women's knowledge and attitudes. Arch Intern Med 1989;149:133.

4. Griffiths F. Women's decisions about whether or not to take hormone replacement therapy: Influence of social and medical factors. Br J Gen Pract 1995;45:477.

5. Livingston WW, Healy JM, Jordan HS, Warner CK, Zazzali JL. Assessing the needs of women and clinicians for the management of menopause in an HMO. J Gen Intern Med 1994;9:385.

6. Marmoreo J, Brown JB, Batty HR, Cummings S, Powell M. Hormone replacement therapy: Determinants of women's decisions. Patient Educ Counseling 1998; 33:289.

7. McNagny S, Jacobson T. Use of postmenopausal hormone replacement therapy by African-American women: The importance of physician discussion. Arch Intern Med 1997;157:1337.

8. American College of Physicians. Guidelines for counseling postmenopausal women about preventive hormone therapy. Ann Intern Med 1992;117:1038.

9. American College of Obstetricians and Gynecologists. American College of Obstetricians and Gynecologists educational bulletin: Hormone replacement therapy. ACOG, Washington, DC, 1998;247:1.

10. U.S. Preventive Services Task Force. Guide to clinical preventive services: Report of the U.S. Preventive Services Task Force, 2nd ed. Baltimore: Williams \& Wilkins, 1996.

11. National Committee for Quality Assurance. Counsel- 
ing patients on options for management of menopausal (MoM) hormonal changes measure, Vol. 2000. National Committee for Quality Assurance; 2000. http://wpww.nega.org accessed July 30, 2000.

12. Greendale G, Carlson K, Schiff I. Estrogen and progestin therapy to prevent osteoporosis: Attitudes and practices of general internists and gynecologists. I Gen Intern Med 1990;5:464.

13. Stafford RS, Saglam D, Causino N, Blumenthal D. Low rates of hormone replacement in visits to United States primary care physicians. Am J Obstet Gynecol 1997;177:381.

14. Seto T, Taira D, Davis R, Safran C, Phillips R. Effect of physician gender on the prescription of estrogen replacement therapy. J Gen Intern Med 1996;11:197.

15. Lacroix A, Neton K, Phelan E. Physician gender and estrogen replacement therapy [Letter]. J Gen Intern Med 1997;12:334.

16. Ghali WA, Freund KM, Boss RD, Rya CA, Moskowitz MA. Menopausal hormone therapy: Physician awareness of patient attitudes. Am J Med 1997;103:3.

17. Berman RS, Epstein RS, Lydick E. Risk factors associated with women's compliance with estrogen replacement therapy. J Women's Health 1997;6:219.

18. Lurie N, Slater J, McGovern P, Ekstrum J, Quam L, Margolis K. Preventive care for women-Does the sex of the physician matter? $\mathrm{N}$ Engl J Med 1993;329:478.

19. Franks $P$, Clancy C. Physician gender bias in clinical decision making: Screening for cancer in primary care. Med Care 1993;31:213.

20. Cauley JA, Cummings SR, Black DM, Mascioli SR, Seeley DG. Prevalence and determinants of estrogen replacement therapy in elderly women. Am J Obstet Gynecol 1990;163:1438.

21. Hurley JS, Frost FJ, Trinkaus KM, Buatti MC, Emmett KE. Relationship of compliance with hormone replacement therapy to short-term healthcare utilization in a managed care population. Am J Managed Care 1998;4:1691.

22. Thompson W. Estrogen replacement therapy in practice: Trends and issues. Am J Obstet Gynecol 1995; 173:990.

23. Keating NL, Cleary PD, Rossi AS, Zaslavskky AM, Ayanian JZ. Use of hormone replacement therapy by postmenopausal women in the United States. Ann Intern Med 1999;13:545.

24. Robinson JG, Folsom AR, Nabulsi AA, Watson R, Brancati FL, Cai J. Can postmenopausal hormone replacement improve plasma lipids in women with diabetes? Diabetes Care 1996;19:480.

25. Lobo R. Benefits and risks of estrogen replacement therapy. Am J Obstet Gynecol 1995;173:982.

26. Stanford JL, Hartge P, Brinton LA, Hoover RN, Brook- meyer R. Factors influencing the age at natural menopause. J Chron Dis 1987;40:995.

27. United States Pharmacopeial Convention I. Drug information for the health care professional: USP DI, 16th ed. Taunton, MA: Rand McNally, USPDI, 1996, Vol. 1.

28. Landis JR, Koch GG. The measurement of observer agreement for categorical data. Biometrics 1977;33:159.

29. Burton P, Gurrin L, Sly P. Expanding the simple linear regression article to account for correlated responses: An introduction to generalized estimating equations and multi-level mixed modeling. Stat Med 1998;17:1261.

30. Zeger SL, Liang K, Albert P. Models for longitudinal data: A generalized estimating approach. Biometrics 1988;44:1049.

31. National Diabetes Data Group. Diabetes in America, 2nd ed. Bethesda, MD: National Institute of Diabetes and Digestive and Kidney Diseases, National Institutes of Health, 1995.

32. Roter DL, Hall JA. Doctors talking with patients, patients talking with doctors. Westport, CT: Auburn House, 1992.

33. Roter DL, Hall JA. Why physician gender matters in shaping the physician-patient relationship. J Women's Health 1998;7:1093.

34. Haar E, Halitsky V, Stricker G. Factors relating to the preference for a female gynaecologist. Med Care 1975; 13:782.

35. Fennema K, Meyer D, Owen N. Sex of physician: Patients' preferences and stereotypes. J Fam Pract 1990; 30:441.

36. Davis D, Thomson M, Oxman A, Haynes B. Changing physician performance. A systematic review of the effect of continuing medical education strategies. IAMA 1995;274:700.

37. Oxman AD, Thomson MA, Davis DA, Haynes RB. No magic bullets: A systematic review of 102 trials of interventions to improve professional practice. $\underline{\text { Can }}$ Med Assoc J 1995;153:1423.

38. Handa VL, Landerman R, Hanlon JT, Harris T, Cohen HJ. Do older women use estrogen replacement? Data from the Duke Established Populations for Epidemiologic Studies of the Elderly (EPESE). J Am Geriatr Soc 1996;44:1.

Address reprint requests to: Sally Huston, M.S. University of Michigan College of Pharmacy 428 Church Street Ann Arbor, MI 48109-1065 


\section{This article has been cited by:}

1. G??lcihan Akkuzu, Kafiye Ero??lu. 2005. The effect of education and counseling services on compliance to therapy of women taking hormone therapy for the first time. Menopause 12:6, 763-773. [CrossRef]

2. Pat Croskerry. 2005. The theory and practice of clinical decision-making. Canadian Journal of Anesthesia/Journal canadien d'anesthésie 52:S1, R1-R8. [CrossRef]

3. Ann K. Boulis , Judith A. Long . 2004. Gender Differences in the Practice of Adult Primary Care PhysiciansGender Differences in the Practice of Adult Primary Care Physicians. Journal of Women's Health 13:6, 703-712. [Abstract] [PDF] [PDF Plus]

4. Debra L. Roter, Judith A. Hall. 2004. Physician Gender and Patient-Centered Communication: A Critical Review of Empirical Research. Annual Review of Public Health 25:1, 497-519. [CrossRef]

5. Molly Carnes, Timothy Howell, Marjorie Rosenberg, Joseph Francis, Christopher Hildebrand, Jeffrey Knuppel. 2003. Physicians Vary in Approaches to the Clinical Management of Delirium. Journal of the American Geriatrics Society 51:2, 234-239. [CrossRef] 